
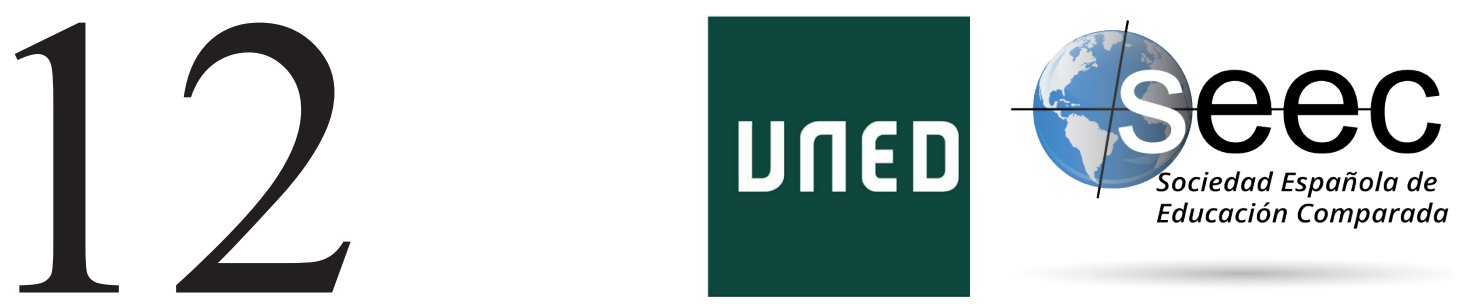

\title{
Las políticas supranacionales de educación superior ante la «tercera misión» de la Universidad: el caso del aprendizaje-servicio
}

Supranacional higher education politics on the "third mission" of University: the case of service-learning

Juan García-Gutiérrez** Carlos Corrales Gaitero**

DOI: $10.5944 /$ reec.37.2021.27535

\author{
Recibido: 18 de mayo de 2020 \\ Aceptado: 30 de julio de 2020
}

\footnotetext{
*Juan García-GutiérRez: Doctor en Pedagogía (con premio extraordinario). Director de la Oficina Universitaria de Aprendizaje-Servicio (UNED) y Coordinador del Grupo de Innovación Docente COETIC. Su área de trabajo es la Filosofía y la Teoría de la Educación, en particular su vertiente político-social y las implicaciones éticas, antropológicas y pedagógicas de los procesos de innovación tecnológica. Es profesor Contratado Doctor en el Departamento de Teoría de la Educación y Pedagogía Social (Facultad de Educación, UNED). Datos de contacto: URL: https://sites.google.com/site/juangarciaedu/Home; ORCID: http://orcid.org/oooo-0oo33966-4069; e-mail: juangarcia@edu.uned.es

**Carlos Corrales Gattero: Doctorando en Educación en la UNED. Su área de trabajo es la Filosofía y la Historia de la Educación. Coordinador de Vinculación con la Colectividad de la Facultad de Ciencias de la Educación de la Pontificia Universidad Católica del Ecuador y miembro del grupo de investigación de Aprendizaje Servicio (GIApS) de la PUCE. Es profesor agregado de la Facultad de Ciencias de la Educación (PUCE). Datos de contacto: ORCID: http://orcid.org/oooo-0001-6903-2375; e-mail: ccorrales680@puce.edu.ec; ccorrales17@alumno.uned.es
} 


\title{
Resumen
}

La evolución que experimentan las instituciones de educación superior y, particularmente, la Universidad supone una (re)consideración de sus formas, metodologías y misiones, así como de las relaciones que establecen con la sociedad. En este sentido, consideramos que la «misión social» de la Universidad o su «tercera misión» constituye un paraguas que cobija una diversidad amplia de conceptos reflejo, a su vez, de esas relaciones entre universidad-sociedad. Además, se considera que el compromiso social y cívico en la educación superior debería incorporar un enfoque integrador, comprometido con una idea de ciudadanía europea o iberoamericana, según sea el caso. Por tanto, el objetivo de nuestro trabajo es doble. De un lado, conocer y analizar la noción de «tercera misión» o «misión social» de la Universidad y su red conceptual, al objeto de clarificar el lenguaje y en qué sentidos se emplean las distintas denominaciones, según los diversos enfoques económicos, de sostenibilidad o cívicos que se adopten. En segundo lugar, se abordará el tratamiento de estas ideas en las políticas supranacionales de educación superior tanto en Europa como Iberoamérica, según han estructurado el Espacio Europeo de Educación Suprior y según han sido promovidas por la OEI. También se atenderá a cómo estas políticas supranacionales abordan los componentes cívicos e identitarios que, ligados a la misión social, colaboran en la promoción de una ciudadanía común. A la luz de los análisis realizados se afirma que el enfoque del aprendizaje-servicio se constituye como una tendencia emergente a escala global, apropiada para desarrollar la tercera misión de la Universidad.

Palabras clave: Dimensión social; Educación superior; Aprendizaje-Servicio; Educación y justicia social; Educación y compromiso social y cívico; Servicio a la comunidad.

\begin{abstract}
The constant transformation that the institutions of higher education experiment and, particularly, the university assumes a re-consideration of their shapes, methodology, and missions, as well as the relationships established with society. Therefore, we shall consider that a "social mission" of the university or their "third mission" constitutes an umbrella that shelters a wide diversity of reflex conceptions, and at the same time, the relationship university - society. Additionally, take into consideration that this civic and social commitment in higher education should incorporate an integrator approach, involved with an idea of European or Latin-American citizenship, in any case, incorporated in the development of their supranational policies. Therefore, the objective of our work is double. On one side, to meet and analyze the notion of a "social mission" or "third mission" of the university and their conceptual network, to clarify the language and in which sense the different denominations are used, according to the different economical, sustainability or civic approaches to be adopted. Secondly, the treatment of these ideas will be addressed at the supranational policies of higher education both in Europe and Ibero America, according to what had been structured at the Higher Education European State and whether it has been promoted by the OEI. Also, it will be attended the way that this supranational policy aboard the civic and identity components, that linked to the social mission cooperate for the promotion of common citizenship. As a result of the analysis made we can affirm that the approach of the learning-service constitutes an emergent tendency on a global scale, appropriate to develop effectively the third mission or social mission of the university.
\end{abstract}

Keywords: Social engagement; Higher education; Service-Learning; Education and social justice; Education and social and civic commitment; Community service. 


\section{Introducción}

Como dejara escrito M. Oakeshott «la forma de la educación ofrecida en la Universidad, como cualquier otra cosa, está sujeta al cambio (2000, 177)». La Universidad, actualmente, está sometida a diferentes tensiones, problemáticas, transformaciones, etc. o, como algunos dicen: «crisis». Esta idea de «crisis de la Universidad» ha generado una abundante literatura, bien reflexionando sobre metodologías nuevas o tradicionales (Gil Cantero y Reyero García, 2015; Esteban Bara, 2019) o, revisando la idea y misión propia de la universidad (Sánchez Cámara, 2010; Brunner, 2014; Ruiz Corbella y Lopéz-Gómez, 2019; Brunner, Labraña, Ganga y Rodríguez-Ponce, 2019). Sin embargo, pensar la Universidad es algo perenne en la preocupación pedagógica e intelectual europea. Baste citar los trabajos clásicos de Ortega y Gasset «Misión en la Universidad» (ed, de 2015 en Cátedra) o «La idea de Universidad» título que comparten sendos trabajos de J. N. Newman (2014) y K. Jaspers (2013). Además de otros apuntes como los de Giner de los Ríos «Escritos sobre la Universidad española» (1990). Qué duda cabe, que parte de ese «boom» bibliográfico de los últimos tiempos se justifica por la necesidad de encontrar respuestas y soluciones a los interrogantes y problemas que abrió a su paso el llamado «proceso de Bolonia».

En este contexto, el objetivo del trabajo es conocer y clarificar el concepto actual de «tercera misión» de la Universidad, así como su uso en las políticas supranacionales de educación superior en los ámbitos europeo e iberoamericano. Para ello, en primer lugar, se analizarán las nociones de «tercera misión» o «misión social», identificando su amplia red conceptual y clarificando el lenguaje pedagógico (Esteve, 2012) según se adopten enfoques económicos, de sostenibilidad o cívicos. En segundo lugar, se abordará su tratamiento en las políticas supranacionales de educación superior, entendidas, como proponen Matarranz y Valle $(2018,101)$, como un estudio de las políticas educativas que emanan de los organismos internacionales indicados, atendiendo a cómo estas inciden en los procesos de integración regional. Ahora bien, en la mayor parte de los casos, las políticas educativas supranacionales se mueven en el ámbito del «soft law». Esto es, documentos o actos jurídicos que, permitiendo a las instituciones u organismos internacionales expresar su punto de vista y sugerir líneas de actuación, no imponen medidas legales coercitivas a quienes se dirigen (Fernández Pons, 2016).

La hipótesis de partida es sencilla. La crisis que experimentan las instituciones de educación superior supone una reconsideración de sus formas, metodologías y misiones. La «misión social» de la Universidad, su «tercera misión», como se la conoce habitualmente, constituye, por su indeterminación, un ámbito poco estudiado pero que arrastra una amplia red de conceptos que reflejan la complejidad de relaciones universidadsociedad. Además, esta «tercera misión» constituye un espacio adecuado para fomentar el compromiso cívico de las instituciones universitarias con los procesos de integración regionales en Europa e Iberoamérica.

\section{Construyendo la noción de compromiso social de la Universidad}

En general, las ideas de «misión social», «tercera misión» o «tercer pilar» de la Universidad podemos entenderlas como sinónimos, en tanto en cuanto se refieren a las 
relaciones que las instituciones de educación superior establecen con la sociedad. A su vez, de estas ideas emerge un amplio conjunto de nociones y conceptos que sirven para matizar e individualizar esas relaciones.

Tradicionalmente, en sus relaciones con la sociedad, aquello a lo que la Universidad ha prestado atención y que no recaía bajo los pilares de docencia o investigación recibía el nombre genérico de «tercer pilar». Quizá sea una de las mejores formulaciones ya que nombra, sin decir nada sustantivo, aquella misión de la Universidad que no se refiere específicamente ni la docencia ni investigación y que por su indeterminación y mutabilidad es mejor mantener sin nombrar de forma concreta. Se trata de una «tercera misión» que todos reconoceríamos, aun sin nombrarla, y que puede adoptar diversas denominaciones específicas, según donde pongamos el acento o según el periodo histórico al que nos referimos.

Por lo tanto, con tercera misión de la Universidad nos referimos, de manera genérica, al conjunto de relaciones que entabla la Universidad con la sociedad. A nuestro juicio, un «alargamiento» de esos beneficios propios de la vida universitaria a la vida social. Por ello, una de las primeras denominaciones de esta misión fue la de «extensión universitaria». Si rastreamos su origen, tenemos que citar la Conferencia sobre el tema celebrada en Cambridge en 1898 (aunque se tienen referencias desde 1872) y citada en el libro de Leopoldo Palacios de 1908 sobre «extensión universitaria» donde ya se planteaba el problema de su denominación conceptual,

«es difícil decir cuál sea el objeto privativo de la university extension, y bien puede estimarse como una de las dificultades mayores la característica que le atribuye Sadler: su infinita diversidad de formas frente a la heterogeneidad del público y los problemas complejos de la educación a cuyo servicio vive. Así, en tanto que algunos autores (como Chabosseau, y no siempre) parecen designar con aquel nombre todo movimiento popular de educación social superior, con carácter privado o público, piensan otros que se refiere solo a la nueva extensión de la enseñanza científica, en cierto modo, llevada por la universidad, que sale de sus confines, al pueblo que trabaja y no puede acudir a ella (Max Leclerc, Buisson, H. Nunn, \& C.), y aun otros todavía que, como Posada entre nosotros, la hacen trascender de la acción pura y exclusiva de la enseñanza, a «toda acción expansiva, de carácter educativo y social, que la Universidad efectúa fuera de su esfera oficial docente». Claro que, según se piense en uno u otro sentido, variarán las instituciones que en ella se comprendan» (Palacios, 1908, p. 126).

Por lo tanto, las complejas y, en ocasiones, problemáticas relaciones entre la Universidad y la sociedad no son tan nuevas como cabría pensar. Para algunos, «la decadencia de la Universidad española es atribuible a muchas causas ciertamente; pero una de ellas y de no escasa importancia, es el alejamiento de la sociedad (p. 54)». Palabras tan actuales hoy, como, parece ser, en 1918 cuando fueron escitas por D. Manuel García Morente (1990). Esta primera idea de «extensión» nos ayuda a concretar y comprender mejor el tipo de relaciones que la universidad entabla con la sociedad para legitimarse, más allá de su consideración como una «torre de marfil» (Barrett, 1998; Stockdill \& Danico, 2012; Chung, 2018). Por ello, la evolución natural de las relaciones entre universidad-sociedad lleva a reconocer que no basta con la mera «extensión» o «difusión» de sus actividades o descubrimientos, sino que es preciso adoptar un mayor «compromiso» o «responsabilidad». 
De esta manera se identifican y florecen diferentes conceptos y denominaciones para concretar en qué consisten las relaciones de compromiso y responsabilidad. Algunos trabajos de revisión conceptual (Cuthill, 2011; Frondizi, Fantauzzi, Colasanti y Fiorani, 2019) han identificado diferentes denominaciones, entre otras: «capacitación a la comunidad», «investigación basada en la comunidad», «investigación colaborativa», «transferencia de conocimiento», «transferencia de tecnología», «extensión», «desarrollo comunitario», «aprendizaje basado en la comunidad», «aprendizaje-servicio», «compromiso cívico», «investigación e innovación responsable», «investigación comprometida», «tercera corriente», «vinculación con la colectividad», «tercer componente de la educación suprior», «compromiso social y de negocios», «tercer pilar», etc.

La abundante terminología se debe, en parte, a la propia diversidad cultural y geográfica en la que nacen y se ubican las instituciones universitarias. Desde esta perspectiva, en el contexto latinoamericano, la idea de «extensión» cabe situarla en 1918 con la «Reforma de Córdoba». Ahora bien, ya en 1843 se dieron los primeros pasos tal y como se recoge en el discurso que diera Andrés Bello (quien siguiendo el esquema francés redactó la Ley orgánica de la Universidad de Chile, y que sirvió de inspiración para las universidades latinoamericanas) al concebir la Universidad como un «cuerpo eminentemente expansivo y propagador» que debía ser «expresión fiel de la vida de la nación, cuyo desarrollo espiritual, educativo y cultural debía promover y presidir» (Tunnermann, 1978, 93 y ss.; Tunnermann, 2000).

El concepto de extensión tomará fuerza en América Latina, sobre todo a principios del siglo XX, como principio rector la justicia social, por cuanto se consideraba una obligación el compartir la cultura y los conocimientos con aquellos menos favorecidos (Serna 2007). Precisamente, el rasgo característico de la universidad latinoamericana a día de hoy es la importante vocación social de la misma, con un gran número (y alta calidad) de productos académicos y aportes a la realidad social poco valorados por los rankings universitarios mundiales (Guaglianone, 2018) pero muy necesarios en una sociedad que demanda formación de profesionales solidarios. Así, se han destacado tres funciones sustantivas de la universidad latinoamericana, que todos los países de la región reconocen en sus leyes de educación superior: docencia, investigación y extensión, las cuales deben interaccionar eficaz y eficientemente con el entorno socio-económico mediante el desarrollo de acciones y proyectos de beneficio mutuo (Rivera, 2019). De esta manera, la extensión desarrolla dos funciones fundamentales. Por una parte, una función integradora y como proceso pedagógico; y, por otro, su papel esencial en el rescate de los saberes populares y la defensa de la identidad nacional (Díaz y Herrera, 2003, pp. 111-112).

En el contexto latinoamericano, la evolución de la idea de extensión ha ido cristalizando en una noción de formación y difusión de la cultura y el conocimiento como forma de «vinculación con la colectividad» (González Ortiz, Yépez-Reyes y García Alarcón, 2019; Zenck, 2019). Desde esta perspectiva podemos identificar diferentes modelos de extensión, tal y como proponen universitaria González, Ávila y Yera (2020) a partir de una revisión sistemática de la literatura científica en la región. 
Tabla 1.

Modelos de extensión universitaria en Latinoamérica

Fuente $\quad$ Modelos de extensión universitaria en Latinoamérica

Altruista: la acción desinteresada y humanitaria de los universitarios a favor de los pobres e ignorantes;

Divulgativo: la ciencia y la cultura universitaria deben rebajarse para ser comprendidos por el pueblo);

Serna (2007) Concientizador: pondera compartir los bienes, incluidos los educativos y culturales, en forma dialógica y liberadora, creando conciencia entre participantes, implica comprender realista y correctamente la ubicación de uno en la naturaleza y en la sociedad.

Vinculatorio empresarial: las necesidades sociales son identificadas como análogas a las de empresas.

Pla, Ramos, Arnáiz, García, Castillo, Soto y Cruz (2012)

\section{Tommasino \& Cano (2016)}

Pedagógico: el proceso de extensión es explicado mediante el proceso educativo y comprende los objetivos, contenidos, métodos, medios, formas organizativas y evaluación.

Difusionista-transferencista: la transferencia de saberes y tecnologías desde la universidad hacia la sociedad, con el objetivo de lograr cambios en la conducta, hábitos o procedimientos de un determinado grupo social en relación a determinado tipo de actividad (productiva, social, sanitaria, etcétera).

Extensión crítica: proceso crítico y dialógico que trascienda la formación tecnológica del profesional para lograr una formación integral.

Fuente: elaboración propia a partir de González, Ávila, y Yera (2020).

Aun reconociendo que algunos términos han podido tener más éxito en uno $\mathrm{u}$ otro contexto no cabe sino afirmar la universalidad de sus significados y pretensiones. Nociones como las de vinculación con la colectividad, difusión y transferencia de conocimiento (Luna Huertas, 2011), responsabilidad social de la universidad (Naval y Ruiz Corbella, 2012), compromiso comunitario o social (Benneworth, et al., 2018) o, incluso, compromiso cívico (Watson, Hollister, Stroud y Babcock, 2011) son ya "patrimonio común» de la educación superior. Por este motivo y en función de dónde pongamos el acento, cabe establecer tres campos semánticos diferentes en los que agrupar la diversidad conceptual que soporta el discurso sobre la tercera misión o misión social de la Universidad: transmisión y transferencia del conocimiento; responsabilidad social y, por último, compromiso social o cívico de la universidad.

\subsection{Difusión y transferencia de conocimiento desde la Universidad}

Con este primer grupo nos referimos a todas aquellas denominaciones que ponen el acento en las relaciones universidad-sociedad y cuyo objeto principal es el desarrollo económico y productivo de un territorio o comunidad, incluyendo las posibilidades de comercialización del conocimiento generado en la Universidad. El foco de la relación se pone en la transferencia de tecnología, la innovación o el emprendimiento y, consecuentemente, en el desarrollo de competencias y formación relacionada con estos ámbitos. La 
postura que mantiene este enfoque es que aquellas instituciones dedicadas a generar y transmitir conocimientos superiores son estratégicas en la «sociedad del conocimiento». Comprender así este tercer pilar o misión llevaría a considerar la universidad como una «universidad emprendedora» (Etzkowitz, Webster, Gebhardt, Terra, 200o; Feldman y Bercovitz, 2006; Guerrero y Urbano, 2010; Wagner; Raposo y Alves, 2011), tal y como recoge la figura 1.

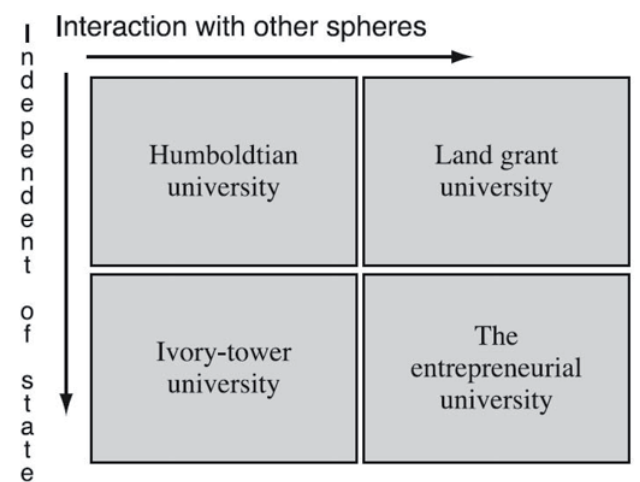

Figura 1: Tipos de universidad. Fuente: Etzkowitz (2003, 112; cit. por Wagner; Raposo y Alves, 2011)

Desde esta perspectiva, la Universidad aparece comprometida y se legitima socialmente por su impacto en el desarrollo económico, la productividad, la transferencia de tecnología y la innovación. En una economía de mercado basada en el conocimiento la aportación social de la Universidad supone una ventaja competitiva fundamental para las empresas. La clave es cómo transferir y comercializar y formar en el conocimiento que genera. Este modelo de transferencia es conocido como de «triple hélice» porque requiere la colaboración de tres agentes sociales: Universidad, empresa y gobierno (Fombuena, 2019). Este modelo es superado por la integración de una cuarta dimensión, la social, generando así un modelo de «quadruple hélice», ampliando así el interés económico al social y, por tanto, se hablar también de transferencia de conocimiento con «valor social». Algo más próximo a las humanidades y ciencias sociales (Castro Martínez, Fernández de Lucio, Pérez Martín y Criado Boado, 2008; Santos Rego, 2020) y que, por tanto, resulta más cercano a la idea de responsabilidad social de la Universidad.

\subsection{La responsabilidad social de la Universidad}

La responsabilidad social de la Universidad (RSU) es un concepto reciente que se caracteriza por una visión más amplia de las relaciones universidad-sociedad (Ruiz-Corbella y Bautista-Cerro, 2016; Martínez-Ussaralde, Gil-Salom y Macías-Mendoza, 2019). La RSU constituye uno de los enfoques más actuales de la governance universitaria, donde la Universidad se presenta como institución socialmente responsable de sus impactos, principalmente ambientales, ante sus stakeholders. En el Informe del MEC (2010) «Estrategia universidad 2015. El camino para la modernización de la Universidad»se incorpora como elemento fundamental de la «tercera misión» la transferencia y la responsabilidad social de la universidad; esto es, una universidad que avance en el concepto de tercera misión, tanto en su aspecto económico relacionado con la transferencia como con la responsabilidad social (p. 24). 
Algunos entienden la RSU de forma crítica y enfrentada al modelo anterior de transferencia de conocimiento (de corte más económico), diferenciando entre aquellos enfoques venidos de América del Norte y Europa, más centrados en una dimensión medioambiental y la concepción latinoamericana que se apoya en la misión social y la vinculación con la colectividad (Vallaeys, 2014). Así, la concepción de RSU transitará de sus inicios relacionadas con el impacto ambiental de las Universidades a posturas más responsables socialmente. Por ejemplo, el Comunicado del Consejo sobre «la dimensión social de la educación y la formación» afirma que,

«La lucha contra la desigualdad, la pobreza y la exclusión social puede fortalecerse si se reconoce que los centros de enseñanza superior tienen la responsabilidad social de devolver a la sociedad los beneficios del conocimiento, de poner este al servicio de la comunidad en sentido amplio, tanto a escala local como mundial, y de responder a las necesidades sociales» (DO UE 2010/C 135/o2, p. 5, de 25/5/2010).

En esta misma línea de responsabilidad se integran las nociones de «investigación e innovación responsable» propuestas por la Comisión Europea en el programa Horizon 2020 o las nociones de «innovación para la exclusión social», la «orientación a desafíos» que ofrecen nuevos marcos teóricos, en los que se da mayor relevancia a los objetivos sociales y a la participación social que a las metas económicas (Vasen, 2016).

\subsection{El compromiso social y cívico de la Universidad}

Para algunos, la responsabilidad social, el compromiso social o cívico y el enfoque del aprendizaje-servicio son formas similares de expresar la tercera misión de la universidad (Martínez, 2008; Pino Loza y Sáenz-Rico, 2014). Todas se caracterizan porque comparten un enfoque de la educación superior basado-en-valores. Estos valores no solo orientan la «tercera misión» sino que informan todas las actividades de la institución, tanto en la investigación como la docencia. La Universidad se presenta responsable y comprometida con valores cívicos o, por ejemplo, con los actuales Objetivos de Desarrollo Sostenible (ODS) o los valores de los derechos humanos. Por ello, esta denominación se identifica con un modelo de «universidad comprometida» o «universidad cívica» (MacIlrth \& Labhrainn, 2007; Watson, Hollister, Stroud \& Babcock, 2011).

Es sabido que los valores cívicos son relevantes por cuanto sostienen y dan sentido a nuestras sociedades democráticas. Pero, además, también son los mimbres con los que las organizaciones internacionales (OEI y UE, en este caso) tejen sus procesos de integración supranacional. En un contexto social de desafección democrática, en el que abundan las fakenews y crece la radicalización y el extremismo violento, comprometer a estudiantes y profesores universitarios con aquellos valores que defienden los derechos humanos o la democracia no puede ser una «tercera misión» sino una misión ineludible de la educación superior (Huber \& Harkavy, 2007; Bergan, Hakavy \& Land, 2013). En los valores más auténticos de la Universidad (como la búsqueda de la verdad o la discusión y el dialogo) se encuentra el antídoto para estos procesos. Además, como se verá a continuación, estos valores entre otros, informan e impulsan los procesos integración regional.

La aportación de este enfoque es relevante para no concebir la educación superior en términos privados y comerciales; valiosa por su empleabilidad y en tanto en cuanto un egresado tiene mejor remuneración económica. El Relator Especial sobre el derecho a la educación, en uno de sus últimos Informes (A/70/342, de 26 de agosto de 2015) critica 
este extremo, apelando a la consideración de la educación como bien social o público y subrayando su misión humanística (p. 22). De esta manera, comprender la misión social de la universidad desde un enfoque de «compromiso cívico», o «basado-en-valores» facilita aquella formación humanística que, en sus más variadas formas, cabría esperar en quienes frecuentan la educación superior. Por este motivo, el enfoque del aprendizaje-servicio (el aprendizaje o la investigación basada en la comunidad) son metodologías apropiadas para promover instituciones universitarias comprometidas cívicamente. Este modelo de universidad entronca con la tradición formativa preocupada por formar el carácter de los estudiantes (Annette \& McLaughlin, 2005).

\section{Las políticas regionales de la UE y la OEI ante la misión social de la Universidad}

En este apartado se analizará cómo se ha gestado políticamente la noción de «dimensión social» en la educación superior a través del proceso de Bolonia, así como las aportaciones de las instituciones comunitarias sobre la misión actual de las Universidades y de la educación superior. En el contexto Iberoamericano nos centraremos, sobre todo, en las conclusiones de las Reuniones de Ministros de Educación de la OEI. Además, se observará si se establecen medidas (o no) en relación a los procesos de integración, por ejemplo, mediante la promoción de unos valores o elementos cívicos comunes.

Tabla 2.

Fuentes documentales europeas e iberoamericanas para estudiar la misión social de la Universidad.

\begin{tabular}{|c|c|}
\hline Contexto europeo & Contexto iberoamericano \\
\hline $\begin{array}{l}\text { Comunicados de las Reuniones } \\
\text { de los Ministros encargados de la } \\
\text { educación superior en el contexto } \\
\text { del EEES (1999 - 2018). }\end{array}$ & $\begin{array}{l}\text { Conferencias Iberoamericanas de } \\
\text { Ministros de Educación (1999 a 2018). }\end{array}$ \\
\hline $\begin{array}{l}\text { Informes del grupo de seguimiento } \\
\text { del Proceso de Bolonia (2012/15 } \\
\text { y } 2015 / 20) \text { e Informes del Grupo } \\
\text { de Trabajo para el desarrollo de la } \\
\text { dimensión social y el aprendizaje } \\
\text { permanente en la Educación } \\
\text { superior }\end{array}$ & $\begin{array}{l}\text { Cumbres Iberoamericanas de Jefes de } \\
\text { Estado y de Gobierno }(2005,2016,2018)\end{array}$ \\
\hline $\begin{array}{l}\text { Comunicaciones de la Comisión } \\
\text { y Conclusiones del Consejo sobre } \\
\text { Educación Superior (2010-2020) }\end{array}$ & $\begin{array}{l}\text { Metas educativas para 2021: La educación } \\
\text { que queremos para la generación de los } \\
\text { bicentenarios (OEI, 2010) }\end{array}$ \\
\hline \multirow[t]{2}{*}{$\begin{array}{l}\text { Declaraciones de la Unión de } \\
\text { Estudiantes Europeos sobre la } \\
\text { Dimensión Social de la Universidad } \\
(2005,2010)\end{array}$} & $\begin{array}{l}\text { Documentos base para las Conferencias } \\
\text { Iberoamericanas de Ministros de } \\
\text { Educación (Creación del Espacio } \\
\text { Iberoamericano del Conocimiento 2006, } \\
\text { Creación y puesta en funcionamiento del } \\
\text { Centro de Altos Estudios Universitarios } \\
\text { Iberoamericanos, 2009) }\end{array}$ \\
\hline & Pacto Iberoamericano de Juventud (2016) \\
\hline
\end{tabular}

Fuente: Elaboración propia` 
En el contexto europeo, la UE y el Consejo de Europea, incluida la OSCE, la identidad y la ciudadanía europea ha sido una asignatura pendiente; quizá por el temor de los Estados a que este tipo de categorías socio-políticas significase, a la larga, una mengua en la propia soberanía y lealtad cívica de sus nacionales. En el caso de la OEI la noción de una identidad común resulta aún más compleja que en la UE. Esto se debe, tanto a la diversidad cultural que encontramos en Latinoamérica como a la propia conciencia nacional de los Estados; así como a la distancia física que separa alguno de los Estados miembros como España o Portugal quienes, además, pertenecen a otras organizaciones regionales.

\subsection{La evolución de la dimensión social de la Universidad en Europa}

En Europa, la noción de «dimensión social» se asocia a las ideas de igualdad de oportunidades y a la tensión por mantener un equilibrio entre desarrollo económico y cohesión social. Cuando en el EEES se menciona la dimensión social se la identifica con el acceso, la participación y la finalización de estudios (Egido Gálvez, Fernández y Galán, 2014) incluyendo, también, la integración laboral de las personas tituladas y otros aspectos relacionados con la responsabilidad social como la innovación y desarrollo regionales y los compromisos sociales de la universidad (Ariño, 2014, 18).

Tomando en cuenta las Declaraciones de las Conferencias Ministeriales se puede observar su evolución, desde las primeras menciones en Praga (2001) y Berlín (2003) hasta la Conferencia de Bergen (2005), que se incluye como parte constitutiva del EEES, definiéndola como aquellas medidas tomadas por los gobiernos para ayudar a los estudiantes (sobre todo, de grupos desfavorecidos) en aspectos relativos a la financiación de estudios y a la orientación y asesoramiento con miras a ampliar el acceso. En las sucesivas Conferencias se reafirman diversos elementos particulares como que el alumnado que ingresa, participa y completa la educación superior debe reflejar la diversidad de la sociedad europea (Londres, 2007). En Lovaina (2009) se ampliará la noción de «misión social» al solicitar que las políticas públicas reconozcan el valor de las diversas misiones de la educación superior, que van desde la docencia y la investigación al servicio a la comunidad y la implicación en la cohesión social y el desarrollo cultural. Además, se reconocen nuevas formas de aprendizaje, nuevos enfoques en la enseñanza y el papel central del estudiante.

El Comunicado de Bucarest (2012) reafirma la dimensión social ante la crisis de 2008. Además, dada la importancia que adquiere, el BFUG (por sus siglas inglesas: Bolonia Folow Up Group) llevará en su programa de 2012/15 el establecimiento de grupo de trabajo sobre aprendizaje permanente y dimensión social (Social Dimension and Lifelong Learning Working Group, SD \& LLL WG) (BFUG, 2012). Dentro de este grupo de trabajo se crearon subgrupos temáticos para abordar temas de acceso, apoyo y servicios estudiantiles, aprendizaje permanente y empleabilidad. Este grupo de trabajo concluye su labor con sendos documentos relevantes sobre el tema. Un Informe del Grupo de trabajo BFUG 12/15 sobre la dimensión social y el aprendizaje permanente (WG SD \& LLL, 2015a) y el documento: «Ampliación de la participación para la equidad y el crecimiento: una estrategia para el desarrollo de la dimensión social y el aprendizaje permanente en el EEES para 2020» (WG SD \& LLL, 2015b).

En el comunicado de Yereván (2015) se incluyen entre los desafíos del EEES, por primera vez, el extremismo y la radicalización. Entre las prioridades está el lograr que la educación superior contribuya efectivamente a la construcción de sociedades inclusivas 
basadas en valores democráticos y en los derechos humanos; y, entre los objetivos, hacer los sistemas de educación suprior más inclusivos a través de la implantación de la estrategia de la dimensión social del EEES. Además, se advierte que para garantizar la calidad educativa es preciso renovar los métodos pedagógicos empleados. En esta Conferencia se insta a la adopción del documento: «Ampliación de la participación para la equidad y el crecimiento: una estrategia para el desarrollo de la dimensión social y el aprendizaje permanente en el Espacio Europeo de Educación Superior para 2020» promovido por el SD \& LLL WG.

La Cumbre Social de Gotemburgo de 2017 impulsó la reflexión sobre esta dimensión social desde el llamado "pilar europeo de los derechos sociales». Tras la Cumbre, la Comisión publicó la Comunicación «Construyendo una Europa más fuerte: el papel de las políticas de juventud, educación y cultura» [COM(2018) 0268 de 22.5.2018] para destacar el papel de estas materias en la construcción del pilar social europeo mediante, por ejemplo, el papel de las redes de universidades: «Universidades europeas» (al menos 20 de estas Universidades hasta 2024) tal y como se había solicitado en las Conclusiones del Consejo. Desde esta perspectiva se promueve una Unión «empoderada» [COM(2018) o268 de 22.5.2018, p. 12] para afrontar los desafíos de: La cercanía, los valores constituyentes del proyecto europeo (paz, seguridad, libertad, democracia, igualdad, estado de derecho, solidaridad y respeto mutuo, mercados abiertos, crecimiento sostenible e inclusión y justicia social) y, por último, el reconocimiento de la diversidad cultural y un sentimiento común de pertenencia.

Por su parte, en el Comunicado de Paris (2018) se incluyen como retos sociales la cuestión migratoria y la radicalización y extremismo violento, así como el proporcionar a los estudiantes oportunidades de aprendizaje continuo para la empleabilidad y para la ciudadanía activa. Se establecen compromisos para el aseguramiento de un futuro sostenible del planeta, alcanzando los ODS. Además, el Comunicado llama a mejorar el apoyo para que los grupos vulnerables e infrarrepresentados accedan y destaquen en la enseñanza superior.

En los sucesivos comunicados se aprecian llamadas a reforzar la identidad europea y los valores comunes, como en el de Berlín (2003) que pide preservar la riqueza cultural y diversidad lingüística basada en la herencia de tradiciones diversa en el EEES a la vez que se promueve una dimensión europea de la educación superior; o el de Londres (2007) que reconoce el papel clave de las instituciones de educación superior en el desarrollo, la definición y transmisión de los valores sobre los que se construyen las sociedades o, como acabamos de ver, también en el de París (2018).

Junto a esta documentación generada por el Proceso de Bolonia, también existen otros documentos donde las Instituciones comunitarias ofrecen sus ideas sobre la misión actual de la Universidad en Europa. 
Tabla 3.

Documentación europea en torno a la misión de la Universidad europea.

\begin{tabular}{|c|c|c|}
\hline Acto jurídico & Denominación & Referencia \\
\hline $\begin{array}{l}\text { Resolución del } \\
\text { Parlamento } \\
\text { Europeo }\end{array}$ & $\begin{array}{l}\text { Modernización de los sistemas de educación supe- } \\
\text { rior en Europa }\end{array}$ & DO C 258 E, de 7.9.2013. \\
\hline $\begin{array}{l}\text { Declaración de } \\
\text { París }\end{array}$ & $\begin{array}{l}\text { Promoción de la ciudadanía y de los valores } \\
\text { comunes de libertad, tolerancia y no discriminación } \\
\text { a través de la educación }\end{array}$ & $(17 \cdot 3 \cdot 2015)$ \\
\hline $\begin{array}{l}\text { Comunicación de } \\
\text { la Comisión }\end{array}$ & $\begin{array}{l}\text { Reforzar la identidad europea mediante la } \\
\text { educación y la cultura }\end{array}$ & $\begin{array}{l}\operatorname{COM}(2017) 673 \text { final, de } \\
14.11 .2017\end{array}$ \\
\hline $\begin{array}{l}\text { Comunicación de } \\
\text { la Comisión }\end{array}$ & $\begin{array}{l}\text { Una Agenda renovada de la UE para la educación } \\
\text { superior }\end{array}$ & $\begin{array}{l}\operatorname{COM}(2017) 247 \text { final, de } \\
30.5 .2017\end{array}$ \\
\hline $\begin{array}{l}\text { Recomendación } \\
\text { del Consejo }\end{array}$ & $\begin{array}{l}\text { La promoción de los valores comunes, la educación } \\
\text { inclusiva y la dimensión europea de la enseñanza }\end{array}$ & $\begin{array}{l}\operatorname{COM}(2018) 23 \text { final de } \\
17.1 .2018\end{array}$ \\
\hline $\begin{array}{l}\text { Resolución del } \\
\text { Parlamento } \\
\text { Europeo }\end{array}$ & Modernización de la educación en la Unión & P8_TA(2018)0247 \\
\hline $\begin{array}{l}\text { Comunicación de } \\
\text { la Comisión }\end{array}$ & $\begin{array}{l}\text { Construyendo una Europa más fuerte: el papel de } \\
\text { las políticas de juventud, educación y cultura }\end{array}$ & $\begin{array}{l}\operatorname{COM}(2018) \text { o268, de } \\
22.5 \cdot 2018\end{array}$ \\
\hline
\end{tabular}

Fuente: Elaboración propia

El primero de los documentos establece una agenda europea para modernizar la Universidad vinculada a la Agenda Europea 2020, para el crecimiento y la ocupación. Agenda que supera la estrategia de Lisboa y que «debe permitir a la Unión alcanzar un crecimiento inteligente, sostenible e integrador, orientado a reforzar el empleo, la cohesión social y territorial (Comisión Europea, 2010). Esta Resolución del Parlamento se justifica por el papel que juega la Universidad y su investigación e innovación en el progreso individual y social; para proporcionar capital humano altamente cualificado y ciudadanos formados que Europa necesita para generar empleo, crecimiento económico y prosperidad. Las Universidades son, por tanto, socios fundamentales para poner en práctica la estrategia de la UE a fin de impulsar y mantener el crecimiento (Comisión Europea, 2011).

Aunque esta Resolución ancla la relación universidad-sociedad en su contribución económica, el resto de documentos amplían este horizonte de relaciones. La «Declaración de París», por ejemplo, afirmará la importancia de los valores comunes de la Unión en respuesta a la radicalización y el extremismo violento (no olvidar que esta Declaración 
responde a los atentados de Paris y Dinamarca de 2015). Así se reafirman los valores fundamentales de la Unión: Respeto a la dignidad humana, libertad (incluida la libertad de expresión), democracia, igualdad, Estado de derecho y respeto de los derechos humanos (p. 3). En este sentido, los Ministros de Educación reunidos en su Consejo de 2016 señalaron que «la finalidad de la educación no debería ser solo la empleabilidad» ya que «otra tarea fundamental es fomentar el respeto por los valores fundamentales comunes a Europa, como la libertad de expresión, la ciudadanía democrática y la igualdad (Consejo de Educación, 2016)». En esta dirección apunta también la Comunicación (2017) «Reforzar la identidad europea mediante la educación y la cultura», donde se apunta a reforzar «el sentimiento de identidad europea y la conciencia del patrimonio cultural» (p. 10).

Por el tema que nos ocupa, el documento más relevante es la Comunicación «Agenda renovada de la UE para la educación superior» que orienta explícitamente esa misión social de la universidad hacia el componente cívico:

«la educación superior debe desempeñar su papel a la hora de enfrentarse a los retos sociales y democráticos de Europa. Esto significa garantizar que la educación superior sea integradora, que esté abierta a los talentos de todas las procedencias y que las instituciones de educación superior no sean torres de marfil, sino comunidades de aprendizaje con conciencia cívica conectadas a sus comunidades» (Comisión Europea, 2017, p. 7).

La misión social de la universidad en el EEES supone una forma de articular las relaciones entre la sociedad y la Universidad en la que cabe distinguir dos sentidos. Un núcleo duro, o un sentido restringido de la «misión social», entendida en términos individuales y centrados en el estudiante: inclusión, acceso, igualdad de oportunidades, participación y retención y éxito en los estudios. De otro, en sentido amplio y cívico, como promoción de todas aquellas relaciones con la sociedad que van más allá de lo económico e implican la promoción de valores e identidad comunes, la diversidad cultural.

Ahora bien, en estas políticas supranacionales, hasta el momento, solo parece existir un desarrollo coherente de la misión social en sentido restringido. Falta, por tanto, un mayor desarrollo de la misión social de la universidad, articulada y vinculada a las nociones de compromiso social y cívico que analizábamos en el punto anterior y que podrían robustecer el sentido de pertenencia a la Unión salvaguardando su diversidad, como reza el lema de la UE.

\subsection{El papel de la Organización de Estados Iberoamericanos (OEI) en la promoción de la dimensión social de la universidad}

Pese a existir diversas organizaciones internacionales de integración supranacional en la región (MERCOSUR, UNASUR, SELA, ALALC, ALBA y CELALC) ninguna lo hace tan claramente desde la educación y la cultura como la OEI que, desde 2005, lidera la creación de un espacio iberoamericano de educación y conocimiento o Espacio Iberoamericano del Conocimiento (EIC) (Calleja, 2017). Su misión es transformar la investigación, el desarrollo y la innovación, incrementar la productividad, «brindando mejor calidad y accesibilidad a los bienes y servicios para nuestros pueblos, así como la competitividad internacional de nuestra región» (OEI, 2005).

Desde sus orígenes en 1949, la OEI apuesta por articular valores comunitarios a través de la educación, sin perder de vista la sociedad global o, más bien, desarrollarlos en 
ella (Molina, 2000) gracias a las posibilidades democráticas y solidarias que se abren paso en un mundo complejo. En los últimos años se refuerzan los aspectos comunes que propicien una visión de Iberoamérica como un conjunto de países con una identidad compartida basada en su herencia cultural (Argüello, 2019), y que, conjuntamente, toman decisiones y asumen retos contribuyendo activamente a la gobernanza global. Sin embargo, no encontramos mayor debate en la Organización sobre el tema identitario. Tal vez porque es un concepto bien asentado en cada una de las leyes nacionales de educación de los países que conforman el área, como demuestra el estudio de MartínezOtero (2019), en el que cada uno de ellos considera prioritario una educación basada en la promoción de los derechos humanos, el desarrollo sostenible, la identidad nacional y la ciudadanía planetaria y, como veremos, la ciudadanía iberoamericana.

Por otra parte, la dimensión social de la universidad en la región iberoamericana se asienta sobre los principios de la Reforma de Córdova, anteriormente citada, y sobre la idea de una gobernanza democrática: ingreso libre y asistencia social a los estudiantes, la formación cultural de los profesionales e impulso a la unidad latinoamericana (Menéndez, 2017). Según este autor, la misión social de la Universidad se resignifica a partir del valor del conocimiento, es decir, la docencia, la investigación y extensión (esta última en particular) se relacionan con el conocimiento adquirido por la comunidad universitaria en tanto que está presente en cada una de sus prácticas y dialoga con los saberes presentes en el medio social, cultural y productivo. Esto «resignifica» los principios de la dimensión social que según Iriarte et al. (2019), a día de hoy, se materializan en los ámbitos de: Igualdad de oportunidades respecto al origen de los estudiantes, el aprendizaje social (educación emocional y educación en valores) y, la inserción laboral, movilidad y empleabilidad. Según estos autores, tan solo con un abordaje integral de estos aspectos, acompañado de una adecuada política pública asegurará hacer frente a las necesidades de la sociedad actual y futura demandante de profesionales comprometidos y con valores cívicos.

Por lo tanto, desde el análisis de los Comunicados emitidos por la OEI, la misión social de la universidad se asocia a tres aspectos fundamentales o líneas estratégicas que cobrarán un impulso especial a partir de la publicación del Informe «Análisis y potencialidades de la cooperación iberoamericana en educación superior» (Secretaría de Cooperación Iberoamericana, 2002) y que, posteriormente, se reforzarán con el documento Metas Educativas 2021: la educación que queremos para la generación de los Bicentenarios (OEI, 2009).

En primer lugar, en relación a la movilidad estudiantil y docente. Las Conferencias de Ministros de educación tratan de consolidar el EIC, a través del refuerzo de la movilidad estudiantil universitaria reconociendo que cuanto más intensos sean los contactos, el diálogo y la cooperación en el EIC, más crecerá la capacidad de crear e innovar y favorecer la construcción de una ciudadanía iberoamericana» (OEI, 2014). En virtud de lo cual se acordará desarrollar un sistema de becas para estudiantes y docentes de programas de grado y posgrado. El Campus Iberoamérica se verá reforzado tras la intención de "promover el diálogo constructivo y las alianzas, entre universidades, polos tecnológicos, empresas y sociedad civil para potenciar el crecimiento económico y la integración regional» (OEI, 2016). Además, se convierte en prioridad culminar el proceso de institucionalización del Espacio Iberoamericano de Cohesión Social para lo que es prioritario el desarrollo de una educación superior comprometida con el desarrollo de la comunidad a través de acciones concretas que lo promuevan vinculándose directamente en proyectos 
de colaboración mutua para lo que la metodología del Aprendizaje Servicio resultará de gran utilidad en el proceso.

En segundo lugar, en relación a la institucionalización de la «extensión» o «vinculación universitaria»: aunque esta sea una función sustantiva de la universidad en toda Latinoamérica, debe avanzar en su institucionalización «redefiniendo funciones específicas y mecanismos eficaces de acción» (Secretaría de Cooperación Iberoamericana, 2002), así como fomentar la «reflexión y la búsqueda de mayores impactos en las actividades de extensión cultural, de difusión de valores y de vinculación de las universidades con la sociedad» (Secretaría de Cooperación Iberoamericana, 2002). En esta dirección apunta el proyecto «Multibien» sobre el análisis multidimensional de las interacciones universidad sociedad que comenzó en 2018 para mejorar la calidad de vida y bienestar de las personas desde el compromiso de la Universidad por abordar los problemas locales (Red Multibien, 2018).

Por último, generar redes de investigación y colaboración. Las políticas comunes, a partir del 2002, irán encaminadas «al reforzamiento de la cultura democrática, la inclusión social y la construcción de ciudadanía» (OEI, 2003), mediante el «desarrollo de la investigación científica y tecnológica, de acuerdo a las necesidades del sector productivo y de desarrollo nacional» (OEI, 2004), estableciendo así, que la investigación es una «herramienta privilegiada para impulsar procesos de integración entre los países de la región» (OEI, 2006). Además, se crea el Centro de Altos Estudios Universitarios Iberoamericano, «institución que se propone contribuir decisivamente a la integración y desarrollo regional, a la mejora de la cualificación de los jóvenes y a la efectiva constitución del Espacio Iberoamericano del Conocimiento» (OEI, 2008) mediante la coordinación de las políticas de intercambio estudiantil y docente y de las redes de colaboración e investigación, utilizadas «como un modelo organizativo para el fortalecimiento institucional, para la articulación de los sistemas nacionales de innovación y para la internacionalización de los mismos» (Sebastián, 2000).

La OEI ha virado ligeramente de rumbo en la consideración de la misión social de la universidad. Mientras que en sus comienzos centra la mayoría de sus esfuerzos en promover el intercambio estudiantil como pilar de la misión social, con el ánimo de promocionar el compromiso cívico y la identidad común iberoamericana, desde el planteamiento de las metas educativas para el 2021 comparte con el EEES la prioridad de la democratización del acceso a la educación superior. Este planteamiento constituye una apuesta firme por consolidar el EIC, a través de la creación de instituciones y políticas comunes que fortalecen las áreas de colaboración educativa y, particularmente, el desarrollo de la dimensión social de la universidad. Es decir, se van creando programas diferentes y según su acogida se crean instituciones para aglutinarlos. Estos organismos van aumentando en número y se insertan dentro de una organización mayor. Es el caso del PIMA y el programa Pablo Neruda por ejemplo, que después se insertan en el CAEU y este, a su vez, en el Campus Iberoamericano que se conforma dentro del EIC (CAEU, 2016). Ahora bien, pese a que las propuestas y esfuerzos hacia la convergencia en materia educativa son cada vez mayores, como hemos analizado, también son poco conocidas entre investigadores y comunidad universitaria, en general.

Al igual que en Europa, en Iberoamérica, acceso, participación y permanencia son rasgos constitutivos de la dimensión social. De este modo se asume que la Universidad no puede estar ajena a las necesidades de la comunidad y tanto la cobertura de su oferta educativa como la democratización de las oportunidades para el acceso y para la obtención de resultados son aspectos básicos de su pertinencia social (Espinosa-Munguía, 2018). 
Por último, cabría mencionar también los «Encuentros de Rectores Universia» que si bien se sitúan al margen de la Organización ayudan a comprender las tendencias políticas supranacionales sobre la misión social ya que estos temas convergen en 2023 con las acciones de la OEI a través de las cumbres de ministros de educación. Hasta el momento se han desarrollado cuatro encuentros, desde 2005. En su primer Encuentro compartieron reflexiones sobre la misión y visión de una universidad humanista bajo el marco del EIC; se plantea un modelo de universidad como motor de un desarrollo sostenible (Universia, 2005). En los encuentros III y IV profundizan en la «dimensión social», apostando por una mayor relevancia y operatividad y se proponen alternativas para fomentar la responsabilidad social y ambiental a través del incremento del acceso a la universidad; la formación en principios, valores y capacidades; el refuerzo de las políticas de género; la atención a grupos con necesidades especiales; la defensa de la inclusión social, el cuidado de un desarrollo más sostenible y equilibrado y la colaboración con su entorno económico y social más cercano (Universia, 2014). En la actualidad se avanza en la contribución de las Universidades al desarrollo social y territorial desarrollando una ciudadanía crítica y ética (Universia, 2018).

\section{El aprendizaje-servicio como enfoque emergente para el desarrollo efectivo del compromiso cívico de la universidad}

Desde una perspectiva supranacional, el aprendizaje-servicio es importante, entre otras razones, porque orienta y dota de contenidos el compromiso cívico de los universitarios. Tanto si este se orienta a la formación de los estudiantes en sus responsabilidades más locales o comunitarias, como si se extiende a la acción y la reflexión hacia comunidades más amplias, de acuerdo con las características propias de la educación superior (García-Gutiérrez, RuizCorbella y del Pozo, 2016), fomentando así una identidad y una pertenencia a la «comunidad total», a la humanidad, cuestionando, como hace Nussbaum (2001), «¿qué tipo de ciudadanos están tratando de producir nuestros establecimientos superiores y en qué medida lo están logrando? (p.21)». Este tipo de cuestiones lleva a la Universidad a reflexionar sobre aquellos valores que le son propios (y no solo sobre argumentos metodológicos-didácticos o administrativos, sobre el tipo de «gobernanza» universitaria más adecuado). Valores tradicionales que han estado en el corazón de las Universidades desde su nacimiento (autonomía y libertad de cátedra) o aquellos otros más contemporáneos como el compromiso o la responsabilidad social. Éstos últimos, cruciales para que las universidades puedan comunicar esa identidad y misión a las partes interesadas, tal y como refleja en el proyecto «Living Values in Higher Education Institutions» de la Universidad de Bolonia.

En los puntos anteriores se ha clarificado y expuesto la evolución de la noción de «tercera misión» o «misión social» de la Universidad. Desde una marginalidad inicial, al centro de las políticas supranacionales de educación superior, sobre todo en el caso europeo. En efecto, es la misma evolución que apreciamos en los valores que han identificado la institución universitaria. De la libertad y la autonomía iniciales a la responsabilidad o el compromiso social o cívico (Gallagher, 2018), más actuales. De la visión de la universidad como una «torre de marfil» a la universidad relacional o interconectada. De esta manera y aunque no aparecen menciones expresas en las políticas supranacionales, podemos considerar el enfoque del aprendizaje-servicio como una tendencia emergente en la educación superior, a escala global, apropiada para responder tanto a la dimensión social de la Universidad como 
al desarrollo particular del compromiso cívico universitario (Aramburuzabala, McIlrath y Opazo, 2019. Así es como, además, lo plantea la literatura científica (Salam, Iskandar e Ibrahim, 2019; Marcus, Atan y Yusof, 2020) y los proyectos que, financiados por la propia Comisión Europea u otras instituciones, refuerzan esta visión.

Tabla 4.

Proyectos de Aprendizaje Servicio financiados por la Comisión Europea.

Denominación Finalidad y objetivos del proyecto

Committing to the social dimension in universities (2013/2016)

University Meets Social Responsability (20152017)

Institucional framework for development of the third mission of universities in Servia (2015-2018)

Developing a culture of civic engagement through service-learning within higer education in Europe $(2016 / 19)$

Service-Learning in Higher Education - Fostering the third mission od the Universities and civic engagement of student (2017/20).

Towars a European Framework for Community Engagement in Higher Education (2018/20)

Aprendizaje-Servicio en la Educación Superior Católica (2019-2022)
Aumentar el compromiso con la dimensión social de la educación superior y apoyar estrategias para aumentar sus resultados. Entre otros objetivos destacan: mejorar la dimensión social de la educación superior en las universidades de Europa e incorporar firmemente la dimensión social en la estrategia y la práctica de las universidades; Promover y apoyar un compromiso de cambio en las universidades de Europa.

(http://commit.eucen.eu)

Mejorar el compromiso de las universidades con las comunidades locales; desarrollar estrategias para que las universidades puedan aumenten su responsabilidad social a nivel de estudiantes e investigadores; desarrollar proyectos de aprendizaje-servicio que impacten en el entorno social; desarrollar material de formación y formar en RSU a estudiantes; crear redes de aprendizaje entre Universidades y empresas locales, el sector ambiental y el sector social.

(https://www.postgraduatecenter.at/en/university-extension/projects/finished-projects/university-meets-social-responsibility-unibility/about-unibility/)

Contribuir al establecimiento de un marco institucional para la tercera misión de las universidades en Serbia, que abarque tres dimensiones: transferencia de tecnología e innovación, educación continua y compromiso social.

(http://www.if4tm.kg.ac.rs)

Identificar la práctica existente de aprendizaje-servicio en Europa y, a la vez, promoverlo como enfoque pedagógico para el desarrollo del compromiso cívico y crear una red sobre aprendizaje-servicio.

(https://europeengage.org)

Desarrollar una estrategia para promover el aprendizaje-servicio, gracias a la cual las universidades cumplan su tercera misión y preparen una nueva generación de profesionales; fortalecer las capacidades de las Universidades relacionadas con el cumplimiento de su tercera misión para mejorar la participación cívica de los estudiantes a través de la implementación del aprendizaje-servicio; mejorar la calidad y relevancia del estudio ofrecido en el campo de la implementación de la estrategia de servicio-aprendizaje en la educación superior. (http://www.slihe.eu/welcome)

Desarrollar herramientas políticas innovadoras y viables a nivel universitario y europeo para apoyar, monitorear y evaluar la participación comunitaria de las instituciones de educación superior.

(https://www.tefce.eu/project)

Generar un cambio sistémico en las Instituciones Católicas de Educación Superior, a través de la institucionalización del aprendizaje-servicio como una herramienta para lograr una educación integral; articulando su alcance social y su identidad espiritual con las actividades académicas. La intención del programa es articular la enseñanza, la investigación y la extensión social alineadas con la misión central de las ICES de integrar su identidad espiritual de un modo innovador para involucrar a la juventud activa como verdaderos agentes de cambio social, que se involucran crítica y solidariamente de acuerdo con la enseñanza social de la Iglesia.

(http://www.clayss.org/uniservitate.html)

Fuente: Elaboración propia a partir de Cayuela, Alonso, Ballesteros, Aramburuzabala (2020). 
El enfoque del aprendizaje-servicio constituye así una propuesta docente y de investigación que integra el servicio a una comunidad con el aprendizaje académico en un proyecto unitario y compacto, que facilita al profesorado la transferencia de conocimiento con valor social y al estudiante formarse sobre la base de la experiencia a partir de necesidades y problemas reales con el objeto de mejorarlos. Desde esta perspectiva, el aprendizaje-servicio conjuga investigación, docencia y transferencia de conocimiento con valor social con necesidades y problemáticas sociales reales de un colectivo. Así se logra vincular y articular de forma coherente los tres pilares o misiones de la Universidad, orientando la propia institución a la búsqueda del bien común.

En efecto, es razonable pensar que las misiones o pilares de la Universidad deben responder a la identidad propia de la institución. Ahora bien, esta identidad ya no puede leerse en términos de la autonomía decimonónica, ni tampoco en términos comerciales como «branding educativo». La fórmula para que la Universidad quede al resguardo de intereses y manipulaciones políticas o mercantilistas debe seguir siendo su compromiso con la búsqueda, el descubrimiento y la transmisión de la verdad y de aquellas formas de vida más humanas y compasivas. El enfoque del aprendizaje-servicio, apuntala esta a una lectura relacional en términos de interdependencia y conexión con el entorno social, empresarial, e incluso con las administraciones públicas. Por esta razón es preciso que las universidades sean espacios de reflexión amplios y plurales, sobre cómo implementar acciones que conecten las misiones de docencia e investigación con aquellas otras responsabilidades y compromisos que la Universidad adquiere con su entorno (tercera misión). Aquí es donde metodologías como el aprendizaje-servicio muestran todo su potencial para conectar y alinear esos tres pilares constitutivos de la identidad universitaria, sin menoscabo de ninguno de ellos. Por lo tanto, el enfoque del aprendizajeservicio cabe entenderlo también a modo de filosofía de la educación superior, ya que, entre otras cosas, vincula y conecta docencia e investigación con aquella misión social y cívica de formar ciudadanos reflexivos y críticos; responsables y comprometidos con sus comunidades locales y supranacionales. Misión que, muy a menudo, queda diluida y eclipsada por aquellas otras más urgentes.

\section{Referencias}

ACUP (2019). Hacer aprendizaje-servicio en la universidad. Recuperado de: https://bit. $\mathrm{ly} / 3 \mathrm{cyKF}_{3} \mathrm{H}$

Annette J. \& McLaughlin, T. (2005). Citizenship and higher education in the UK. En J. Arthur \& K. Bohlin (Eds.) Citizenship and higher education. The role of universities in communities and socity. London: Routledge Falmer.

Aramburuzabala, P. McIlrath, L. y Opazo, H. (eds.) (2019). Embedding Service Learning in European Higher Education. Developing a Culture of Civic Engagement. Londres: Routledge.

Argüello, J. (2019). Europa e Iberoamérica: entre la integración y el soberanismo. Relaciones Internacionales, 28(56), 233-244. Recuperado de: https://bit. ly/2BGBnoP

Ariño Villaroya, A. (2014). La dimensión social en la educación superior. RASE Revista de Sociología de la Educación, 7(1), 17-41. Recuperado de: https://bit.ly/3e1lGWz 
Barret, B. (1998). What is the function of a university? Ivory tower or trade school for plumbers? Quality Assurance in Education, 6.3, 145-151. Recuperado de: https:// bit.ly/3gsEHCN

Benneworth, P., Culum, B., Farnell, T., Kaiser, F., Seeber, M., Scukanec, N., ... Westerheijden, D. (2018). Mapping and critical synthesis of current state-ofthe-art on community engagement in higher education. Zagreb: Institute for the Development of Education. Recuperado de: https://bit.ly/31KDJh5

Bergan, S. Hakavy, I. \& Land, H. (2013). Reimagining democratic societies. A new era of personal and social responsibility. Strabourg: Council of Europe Publishing.

BFUG (2012). Establecimiento del Grupo de trabajo sobre Dimensión social y aprendizaje a lo largo de la vida. Recuperado de: https://bit.ly/2TfLeHL

Brunner, José Joaquín (2014). La idea de la Universidad pública en América Latina: Narraciones en escenarios divergentes. Educación XX1, 17(2), 17-34. https://doi. org/10.5944/educxx1.17.2.11477

Brunner, J. J.; Labraña, J.; Ganga, F. y Rodríguez-Ponce, E. (2019). Idea moderna de Universidad: de la torre de marfil al capitalismo académico. Educación XX1, 22(2), 119-140. https://doi.org/10.5944/educxx1.22480

CAEU. (2016). OEI: CAEU movilidad. Recuperado de CAEU: https://bit.ly/3g1yPAX

Calleja, G. (2017). El espacio iberoamericano de educación superior. Nueva revista, 163, 405-415. Recuperado de: https://bit.ly/38ANK1R

Castro Martínez, E.; Fernández de Lucio, I; Pérez Martín, M. y Criado Boado, F. (2008). La transferencia de conocimientos desde las humanidades: posibilidades y características. Arbor, 184(732), 619-636. https://doi.org/10.3989/arbor.2008. i732.211

Cayuela A., Alonso M., Ballesteros C., Aramburuzabala P. (2020). 2019 Annual Report of the European Observatory of Service-Learning in Higher Education. Recuperado de: https://bit.ly/2XoBoum

Chung, H. (2018). The idea of the university: National asset or ivory tower? In Heijnen A. \& Van der Vaart R. (Eds.), Places of Engagement: Reflections on Higher Education in 2040 - A Global Approach (pp. 136-141). Amsterdam: Amsterdam University Press.

Comisión Europea (2010). Europa 2020. Una estrategia para un crecimiento inteligente, sostenible e integrador. COM (2010) 2020 final de 3.3.2010. Recuperado de: https://bit.ly/2VOQd3t

Comisión Europea (2011). Comunicación de la Comisión al Parlamento Europeo, al Consejo, al Comité Económico y Social Europeo, y al Comité de las Regiones Apoyar el crecimiento y el empleo. Una agenda para la modernización de los sistemas de educación superior en Europa, COM (2011) 0567 final. Recuperado de: https://bit. ly/2VQy2ut 
Comisión Europea (2017). Comunicación de la Comisión al Parlamento Europeo, al Consejo, al Comité Económico y Social Europeo y al Comité de las Regiones sobre una Agenda renovada de la UE para la educación superior. COM(2017) 247 final. Recuperado de: https://bit.ly/2ZDf37M

Comisión Europea (2018). Comunicación Construyendo una Europa más fuerte: el papel de las políticas de juventud, educación y cultura. COM(2018) o268 de 22.5.2018. Recuperado de: https://bit.ly/2Auo6iC

Conferencia de Ministros Europeos de Educación Superior. (2001). Declaración de Praga: Hacia el Área de la Educación Superior Europea. Recuperado de: https:// bit.ly/3cNCH6Y

Conferencia de Ministros Europeos de Educación Superior. (2003). Comunicado de la Conferencia de Berlín: Educación Superior Europea. Recuperado de: https://bit. ly/2WEPS4g

Conferencia de Ministros Europeos de Educación Superior. (2005). Comunicado de la Conferencia de Bergen: El Espacio Europeo de Educación Superior: Alcanzando las metas. Recuperado de: https://bit.ly/2ygyUQu

Conferencia de Ministros Europeos de Educación Superior. (2007). Comunicado de la Conferencia de Londres: Hacia el Espacio Europeo de Educación Superior: respondiendo a los retos de un mundo globalizado. Recuperado de: https://bit. ly/2XagxoL

Conferencia Europea de Ministros de Educación Superior. (2012). Comunicado de la Conferencia de Bucares: Making the Most of Our Potential: Consolidating the European Higher Education Area. Recuperado de: https://bit.ly/3cFwAS4

Conferencia Europea de Ministros de Educación Superior. (2015). Comunicado de la Conferencia de Everán. Recuperado de: https://bit.ly/3bENdMo

Conferencia de Ministros Europeos de Educación Superior. (2018). Comunicado de la Conferencia de París. Recuperado de: https://bit.ly/2ZddI8V

Consejo de Educación (2016). Información de la reunión del Consejo de Educación, Juventud, Cultura y Deporte, 24 de febrero de 2016. Recuperado de: https://bit. ly/2LFoFZ3

Cuthill, M. (2011). Embedding engagement in an Australian 'Sandstone' University: from community service to University Engagement. Metropolitan Universities, 22(2), 21-44. Recuperado de: https://bit.ly/31NUecy

Díaz, C. y Herrera, L. (2003). Extensión Universitaria. En J. C. Pugliese (ed.). Políticas de estado para la universidad argentina. Balance de una gestión en el nuevo contexto nacional e internacional (pp. 111-117). Buenos Aires: Ministerio de Educación, Ciencia y Tecnología. Recuperado de: https://bit.ly/2ZEhYNh

Egido Gálvez, I., Fernández Díaz, M., \& Galán, A. (2014). La dimensión social del proceso de Bolonia: apoyos y servicios para grupos de estudiantes poco representados en las universidades españolas. Educación XX1, 17(2). https://doi.org/10.5944/ educxx1.17.2.11479 
Espinosa-Munguía, M. S. (2018). Tendencias recientes de la vinculación universitaria con el entorno. Desafíos relacionados con una pertinencia social integral. Revista Iberoamericana de Educación Superior, 9(26), 110-129. http://dx.doi. org/10.22201/iisue.20072872e.2018.26.299

Esteban Bara, F. (2019). La universidad light. Un análisis de nuestra formación universitaria. Barcelona: Paidós.

Esteban Bara, F. (2018). Ética del profesorado. Barcelona: Herder.

Esteve, J. M. (2012). Educar. Un compromiso con la memoria. Barcelona: Octaedro.

Etzkowitz, H., Webster, A., Gebhardt, C. \& Terra, B. (2000). The Future of the University and the University of the Future: evolution of ivory tower to entrepreneurial paradigm. Research Policy, 29, 313-330. https://doi.org/10.1016/Soo487333(99)00069-4

Fernández Pons, X. (2016). Fuentes de derecho de la Unión Europea: derecho derivado. En V. M. Sánchez (Dir.) Derecho de la Unión Europea (pp. 159-170). Barcelona: Huygens.

Feldman, M. y Bercovitz, J. (2006). Entrepreneurial Universities and Technology Transfer: A Conceptual Framework for Understanding Knowledge-Based Economic Development. Journal of Technology Transfer, 31(1), 175-188. https:// doi.org/10.1007/s10961-005-5029-Z

Fombuena, A. (2019). Evaluación de la transferencia de conocimientos e innovación de las universidades españolas. Revista española de documentación científica, 42(3), 1-14. https://doi.org/10.3989/redc.2019.3.1596

Frondizi, R.; Fantauzzi, C.; Colasanti, N. \& Fiorani, G. (2019). The evaluation of Universities' third misión and intelectual capital: theoretical analysis and application to Italy. Sustainability, 11, 1-23. https://doi.org/10.3390/su11123455

Gallagher, T. (2018). Promoting the civic and democratic role of higher education: the next Challenge for the EHEA? En L. Deca \& R. Pricopie (eds.) European higher Education Area: The Impact of Past and Future Policies (pp. 335-345). NY: Springer. https://doi.org/10.1007/978-3-319-77407-7_21

García-Gutiérrez, J.; Ruiz-Corbella, M.; y del Pozo, A. (2016). Cuando la comunidad se expande ciudadanía global y aprendizaje-servicio virtual (apsv). Educación y diversidad, 1O(2), 63-75. Recuperado de: https://bit.ly/2NZJAXX

García Morente, M. (1975). La autonomía de la Universidad y el Estatuto de la Universidad de Madrid. En Escritos pedagógicos (pp. 53-74). Madrid: Espasa Calpe.

Gil Cantero, F. y Reyero García, D. (2015) (Eds.) Educar en la universidad de hoy. Propuestas para la renovación de la vida universitaria. Madrid: Encuentro.

Giner de los Ríos, F. (1990). Escritos sobre la Universidad. Madrid: Espasa Calpe. 
González, M., Ávila, M., \& Yera, A. (2020). La gestión del proceso de extensión universitaria: sistematización teórica. Estrategia y Gestión Universitaria, 8(1), 1-16. Recuperado de: https://bit.ly/3f1rAYV

González Ortiz, J. C.; Yépez-Reyes, V. y García Alarcón, E. (2019) (Eds). Vinculación con la colectividad: una propuesta de gestión. Quito: PUCE.

Guaglianone, A. (2018). Los rankings internacionales y el posicionamiento de América Latina. Una mirada reflexiva. CTS, 13(37), 113-126. Recuperado de: https://bit. ly/2VOTBeH

Guerrero, M \& Urbano, D. (2010). The development of an entrepreneurial university. Journal of Technology transfer, 29(4), 235-246. https://doi.org/10.1007/s10961010-9171-X

Huber, J. \& Harkavy, I. (2007). Higher education and democratic culture. Citizenship, human rights and civic responsibility. Strabourg: Council of Europe Publishing.

Iriarte, C., Morales, R., Cruz, L., Malta, J., Paz, C., Medina, M., ... Tamashiro, R., (2019). La dimensión social en la educación superior para las instituciones formadoras de docentes: una mirada desde Latinoamérica. Revista de sociología de la educación, 12(2), 245-265. Recuperado de: https://bit.ly/31Pl1F8

Jaspers, K. (2013). La idea de la universidad. Pamplona: Eunsa.

Luna Huertas, J. C. (2011). La tercera misión de la universidad iberoamericana. La transferencia de conocimiento y la innovación en la universidad iberoamericana. Madrid: Académica Española.

Marchesi, A. (2009). Las Metas Educativas 2021. Un proyecto iberoamericano para transformar la educación en la década de los bicentenarios. Revista Iberoamericana de Ciencia, Tecnología y Sociedad, 4(12), 87-157. Recuperado de: https://bit. ly/31NKE9d

Marcus, V. B.; Atan, N. A. \& Yusof, S. M. (2020). A systematic review of e-service learning in higher education. International Journal of Interactive Mobile Technologies. 14(6), 4-14. Recuperado de: https://bit.ly/2BxnA4d

Martínez-Otero, V. (2019). Claves axiológicas y retos educativos en Iberoamérica. Revista Iberoamericana de Educación, 8o(2), 105-127. https://doi.org/10.35362/ rie8023316

Martínez, M. (2008). Aprendizaje servicio y responsabilidad social de las universidades. Barcelona: Octaedro. Recuperado de: https://bit.ly/2BFoYi5

Martínez-Ussaralde, Ma . J.; Gil-Salom, D. y Macías-Mendoza, D. (2019). Revisión sistemática de responsabilidad social universitaria y aprendizaje-servicio. Análisis para su institucionalización. Revista Mexicana de Investigación Educativa, 24(80), 149-172. Recuperado de: https://bit.ly/38sEFZ3

MacIlrth, L. \& Labhrainn, M. I. (2007). Higher Education and Civic Engagement: international Perspectives. Aldershot: Ashgate. 
Matarranz, M. y Valle, J. (2018). Educación y supranacionalidad: aproximación a los conceptos básicos. Journal of Supranational policies of Education, 8, 93-107.

MEC (2010). Estrategia Universidad 2015. Madrid: MEC. https://doi.org/10.15366/ jospoe2018.8.006

Menéndez, G. (2017). Resignificación de la extensión a 100 años de la Reforma Universitaria de 1918. Revista $+E, 7(7), 24-37$. https://doi.org/10.14409/extension. voi7.7048

Molina, F. (2000). Educación, Multiculturalismo e Identidad. Madrid: OEI.

Naval, C. y Ruiz Corbella, M. (2012). Aproximación a la responsabilidad social universitaria. La respuesta de la universidad a la sociedad. Bordón, 64(3), 102-115. Recuperado de: https://bit.ly/3e21q75

Newman, J. H. (2014). Una idea de Universidad. Madrid: Encuentro.

Nussbaum, M. C. (2001). El cultivo de la humanidad. Una defensa clásica de la reforma en la educación liberal. México: Andrés Bello.

Oakeshott, M. (2000). El Racionalismo en la política y otros ensayos. México DF: Fondo de Cultura Económica.

OEI. (2002). XII Conferencia Iberoamericana de Ministros de Educación. Santo Domingo. Recuperado de: https://bit.ly/31M9aYv

OEI. (2003). XIII Conferencia Iberoamericana de Ministros de Educación. Tarija. Recuperado de: https://bit.ly/2VOmVly

OEI. (2004). XIV Conferencia Iberoamericana de Ministros de Educación. San José. Recuperado de: https://bit.ly/2YZ1vnK

OEI. (2005). XV Cumbre Iberoamericana de Jefes de Estado y de Gobierno. Salamanca. Recuperado de: https://bit.ly/3ize54U

OEI. (2006). XVI Conferencia Iberoamericana de Ministros de Educación. Montevideo. Recuperado de: https://bit.ly/3gsLgVX

OEI. (2008). XVIII Conferencia Iberomericana de Ministros de Educación. Salinillas. Recuperado de: https://bit.ly/3e3ny15

OEI. (2009). 2021. Metas educativas. la educación que queremos para la generación de los bicentenarios. Madrid: OEI. Recuperado de: https://bit.ly/38s8F78

OEI. (2012). XXII Conferencia Iberoamericana de Ministros de Educación. Salamanca. Recuperado de: https://bit.ly/3glK9aG

OEI. (2014). XXIV Conferencia Iberoamericana de Ministros de Educación. México. Recuperado de: https://bit.ly/2ZBWTTW

OEI. (2016). XXV Cumbre Iberoamericana de Jefes de Estado y de Gobierno: Juventud, emprendimiento y educación. Cartagena de Indias. Recuperado de: https://bit. ly/3gr6Ytx 
OEI. (2018). XXVI Cumbre Iberoamericana de Jefes de Estado y de Gobierno. Guatemala. Recuperado de: https://bit.ly/2NZmpgc

Ortega y Gasset, J. (2015). Misión de la Universidad. Madrid: Cátedra.

Palacios, L. (1908). Las universidades populares. F. Sempere y Compañía Editores: Valencia. Recuperado de: https://bit.ly/2BISdno

Pino Loza, E., \& Sáenz-Rico de Santiago, M. B. (2014). La dimensión social de la universidad del siglo XXI: creación del programa de aprendizaje-servicio en la Universidad Técnica de Ambato. Revista Iberoamericana de Educación, 65(1), 1-11. https://doi.org/10.35362/rie651334

Posada, A. (1911). La extensión universitaria. Archivos de pedagogía y ciencias afines, 8(23), 217-232. Recuperado de: https://bit.ly/2X6ENIb

Red Multibien (2018). Análisis multidimensional de las interacciones universidadsociedad en Iberoamérica. Enfoque teórico y metodológico de los greupos de la red en relación con la interacción universidad-sociedad y su contribución al bienestar. Recuperado de: https://bit.ly/2LFq8yx

Rivera, C. (2019). Sobre la función social del conocimiento humano mediante la vinculación y transferencia del conocimiento en América Latina. Revista de Educación Superior, 48(189), 121-132. Recuperado de: https://bit.ly/2BFomsM

Ruiz-Corbella, M. y López-Gómez, E. (2019). La misión de la universidad en el siglo XXI: comprender su origen para proyectar su futuro. Revista de Educación Superior, 48(189), 1-19. https://doi.org/10.36857/resu.2019.189.612

Ruiz-Corbella, M., \& Bautista-Cerro Ruiz, M. (2016). La responsabilidad social en la universidad española. Teoría De La Educación. Revista Interuniversitaria, 28(1), 159-188. http://dx.doi.org/10.14201/teoredu2016281159188

Salam, M., Iskandar, D. N. y Ibrahim, D. H. (2019). Service learning in higher education: a sistematic review. Asia Pacific Education Review, 20, 573-593. https://doi. org/10.1007/s12564-019-09580-6

Sánchez Cámara, I. (2010). Pluralidad de misiones en el Espacio Europeo de Educación Superior. Madrid: Estudia XXI - FESE.

Santos Rego, M. A. (ed.) (2020). La transferencia de conocimiento en educación. Un desafio estratégico. Madrid: Narcea.

Sebastián, J. (2000). Las redes de cooperación como modelo organizativo y funcional para la I+D. Redes, 7(15), 97-111. Recuperado de: https://bit.ly/2NYlooI

Secretaría de Cooperación Iberoamericana. (2002). Análisis y potencialidades de la cooperación iberoamericana en el ámbito de la Educación Superior. Madrid: OEI. Recuperado de: https://bit.ly/2ZDJbzQ

Serna Alcántara, G. A. (2007). Misión social y modelos de extensión universitaria: del entusiasmo al desdén. Revista Iberoamericana de Educación, 43(3), 1-7. Recuperado de: https://bit.ly/31OosZY 
Stockdill, B. C., \& Danico, M. (Eds.) (2012). Transforming the Ivory Tower. Honolulu: University of Hawaii Press.

Tünnermann Bernheim, C. (1978). El nuevo concepto de extensión universitaria y difusión cultural y su relación con las políticas de desarrollo cultural en América Latina. Anuario de Estudios Centroamericanos, 4, 93-126. Recuperado de: https:// bit.ly/3ixAjEE

Tünnermann Bernheim, C. (2000). Pertinencia social y principios básicos para orientar el diseño de políticas de educación superior. Educación Superior y Sociedad, 11(12), 181-196. Recuperado de: https://bit.ly/31MEsio

Vasen, F. (2016). ¿Estamos ante un "giro poscompetitivo" en la política de ciencia, tecnología e innovación? Sociológicas, 18(41), 242-268. https://doi. org/10.1590/15174522-018004112.

Vallaeys, F. (2014). La responsabilidad social universitaria: un nuevo modelo universitario contra la mercantilización. Revista Iberoamericana de educación superior, 5(12) 105-117. Recuperado de: https://bit.ly/3gqpdPK

Wagner, E.; Raposo, M. y Alves, H. (2011). The process of change in university management: from the "Ivory tower" to entrepreneurialism. Transylvanian Review of Administrative Sciences, 33, 124-149. Recuperado de: https://bit.ly/3iHHWsa

Watson, D.; Hollister,R.; Stroud, S. y Babcock, E. (2011). The engaged University. International perspectives on civic engagement. London: Routledge.

WG SD \& LLL (2015a) Informe sobre la dimensión social y el aprendizaje permanente. Recuperado de: https://bit.ly/3fVS1QK

WG SD \& LLL (2015b). Ampliación de la participación para la equidad y el crecimiento: una estrategia para el desarrollo de la dimensión social y el aprendizaje permanente en el EEES para 2020. Recuperado de: https://bit.ly/3g10uVW

Universia (2005). I Encuentro Internacional de Rectores de Universia. La universidad iberoamericana en la sociedad del conocimiento. Sevilla: Banco Santander. Recuperado de: https://bit.ly/2NZAcne

Universia (2014).III Encuentro Internacional de Rectores Universia. Carta Universia Río 2014: Claves estratégicas y propuestas para las universidades iberoamericanas. Río de Janeiro: Banco Santander. Recuperado de: https://bit.ly/2NZAiLC

Universia (2018). IV Encuentro Internacional de Rectores. (2018). Declaración de Salamanca. Salamanca: Banco Santander. Recuperado de: https://bit.ly/2ZoGyZF

Zenck, M. C. (2019). Análisis institucional de los modelos de vinculación con la sociedad de las universidades en el Ecuador. Quito: PUCE. Recuperado de: https://bit. ly/2Z3KCsl 